\title{
FORST ON REGIPROCITY OF REASONS: A CRITIQUE
}

Abstract: According to Rainer Forst, (i) moral and political claims must meet a requirement of reciprocal and general acceptability (RGA) while (ii) we are under a duty in engaged discursive practice to justify such claims to others, or be able to do so, on grounds that meet RGA. The paper critically engages this view. I argue that Forst builds a key component of RGA, that is, reciprocity of reasons, on an idea of reasonableness that undermines both (i) and (ii): if RGA builds on this idea, RGA is viciously regressive, and a duty of justification to meet RGA is not agent transparent. This result opens the door for alternative conceptions of reciprocity and generality. I suggest that a more promising conception of reciprocity and generality needs to build on an idea of the reasonable that helps to reconcile the emancipatory or protective aspirations of reciprocal and general justification with its egalitarian commitments. But this requires downgrading RGA in the order of justification and to determine on prior, substantive grounds what level of discursive influence in reciprocal and general justification relevant agents ought to have.

\section{INTRODUCTION}

Rainer Forst has developed a conception of moral and political justification that puts center stage a requirement of reciprocal and general acceptability. ${ }^{1}$ According to Forst, (i) moral and political normative claims must meet

Thomas M. Besch is Luojia Professor of Philosophy at Wuhan University. His primary area of research is social and political philosophy, recently with a focus on ideas of public reason and conceptions of legitimacy, inclusion, equality, and discursive respect. He has published widely in this area.

${ }^{1}$ Forst draws on many sources, but two early influences continue to resonate in his work. These are Habermas's discourse ethics and Rawls's political liberalism (see Forst 1994, chap. 4, and Forst 2010). Forst aims to combine a Kantian form of moral constructivism with a Rawls-type political constructivism (although he more recently moves to a strong Kantian reading of Rawls's political liberalism; see Forst 2017b). For Forst, a requirement of reciprocal and general acceptability is at the heart of both kinds of constructivism. 
a requirement of reciprocal and general acceptability - or RGA, for shortwhile (ii) we, real agents, are under a duty in engaged discursive practice to justify our moral and political claims to others, or be able to do so, on grounds that meet RGA. This paper critically engages this view. I argue that Forst construes a key element of RGA - that is, the idea of a "reciprocity of reasons" (Forst 2010, 719)-in terms that undermine both (i) and (ii). Before I elaborate further, let me sample three of the many respects in which RGA is central for Forst's view.

First, RGA is at the heart of Forst's justification-centric view of practical reason. This view is constructivist in that it defines the justification, or validity, of moral and political normative claims as a function of their reciprocal and general acceptability (2017a, 1-18). Accordingly, for Forst, practical reason is a "capacity to respond to practical questions in appropriate ways with justifying reasons" (Forst 2012, 18). And it is "the principle of reason" (Forst 2017a, 6) that salient claims be justifiable "in precisely the manner referred to by their validity claims" (6). Thus, "practically reasonable beings... 'stand behind' their validity claims and duties of justification, that is, they are ready and able not only to provide adequate reasons, but also to make them the foundation of their actions" (6). Yet the validity claims of moral and political claims are such that these claims must be justifiable on reciprocally and generally acceptable grounds (Forst 2010). Practical reasonableness hence involves a readiness and ability to comply with one's duty of justification to meet RGA.

Second, RGA takes center stage in Forst's substantive view of justice. For Forst, a political order is just only if it accords with principles that are justifiable to every affected person on reciprocally and generally acceptable grounds. Accordingly, only a "basic structure of justification" (Forst 2017a, 4) that complies with RGA one that treats each citizen as "equal participants and normative authorities" of justification (Forst 2017a, 134, 6ff; 2015a, 825; 2015b, 112) - can fully respect the basic right to justification of citizens. This, in turn, enables "fundamental" justice, political legitimacy, real democracy, or true nondomination (Forst 2012, 6, 213-16; 2017a, 4, 6f, 131-37). Forst conjectures that justifications that comply with RGA can establish as justified, or valid, rights to individual liberty and political participation and rights to resources that enable or support the usage of these rights (Forst 2012, 225f, 262).

Third, RGA ties Forst's constructivism to his understanding of critical theory. Critical theory connects "reflection in philosophy and social science informed by an interest in emancipation" (Forst 2017a, 1). As such, it examines "orders and relations of justification" (2) - or justification practices, for 
short - in light of a view of what justification practices should be like, given salient emancipatory aims. Critical theory hence takes it that "the first question of justice" is the question of "the justifiability of social relations and the distribution of the "power of justification' within a political context" (Forst 2012, 4f). But justification practice allocates to people a proper measure of such power only if it complies with RGA. Specifically, justification practice that complies with RGA accords each relevant agent a "qualified veto right" (Forst 2010, 719) in matters that relevantly affect the agent. This not only respects the agent's right to justification, it also protects, or helps to protect, the agent "from unjustified domination" (Forst 2001, 168f). ${ }^{2}$ This implicates

2 a justification-centric view of (non)domination. Domination here "means being disrespected in one's basic claim to be a free and equal normative authority [of justification] within the order one is subject to, and that implies the basic right to co-determine the structure of that society" (Forst 2016, 23). Accordingly, nondomination requires that exercises of power respect each affected person as a free and equal discursive authority. Yet, for Forst, to respect people accordingly involves respecting their qualified veto rights. RGA hence requires justification practices to accord relevant people a kind of discursive standing that aligns these practices with critical theory's emancipatory commitments.

In short, much here hinges on whether we can tell (individually or collectively, at least provisionally) whether salient claims are justifiable on reciprocally and generally acceptable grounds. After all, a standard, S, can hardly serve as a standard of justification, or validity, for actual agents if it is not within their genuine reach to identify whether salient claims meet S. Can we identify whether salient claims meet RGA? I argue that this is not so. For Forst, claims meet RGA only if they satisfy a requirement of reciprocity of reasons. On one reading of what this calls for, RGA must be rejected. On another initially promising reading, RGA is viciously regressive. Either way, RGA cannot serve as a standard of justification, or validity, for engaged discursive practice and we, real people, are not under a duty to (be able to) justify ourselves to others on grounds that meet RGA. ${ }^{3}$

2 See also Forst (2017a, 1-21, 37-51, 131-51; 2014, 178-81, 187-200; Forst 2016, 23f.).

3 Recent debate has seen sympathetic criticisms of Forst's account of reciprocity and generality (see Alan 2014; Laden 2014; Benhabib 2015; White 2015; Besch 2015; McGuire 2016; McNay 2020). These authors sympathize with the egalitarian and emancipatory aspirations that resonate in Forst's account, but argue that the requirement of reciprocal and general acceptability does not accomplish what Forst hopes it to accomplish. My discussion joins this chorus (though for reasons other than the ones advanced in these texts). And I pinpoint a respect in which that requirement needs revision to better serve such aspirations. 
This result has a positive upshot. It opens the door for conceptions of reciprocity and generality that draw on different ideas of the reasonable and that hence differ in content. It also complicates matters. It makes RGA's (putative) authority as a standard of justification dependent on whether RGA adopts a permissible, duly justifiable idea of the reasonable. It is open what idea of the reasonable may be adopted here. However, any idea that may come in must allocate to relevant people a due measure of discursive influence in justification, or discursive standing of high "discursive purchase," that reconciles RGA's egalitarian commitments with its emancipatory aspirations. This calls for substantive considerations beyond RGA's purview.

I proceed as follows. Sections 2 and 3 reconstruct RGA with a focus on reciprocity of reasons. Forst adopts a pro tanto promising version of RGA (referred to below as RGA-r) that requires justifications on "reasonably" nonrejectable grounds. Section 4 addresses Forst's view that people have a duty of justification to meet RGA-r. Section 5 shows that RGA-r is viciously regressive if it is understood in Forst's terms. Section 6 considers, and dismisses, attempts to save RGA-r from this problem. Section 7 argues that we do not have a duty of justification to meet RGA-r. Section 8 draws out implications of this result by elaborating on a particularly important respect in which RGA's content stands to be recalibrated. Section 9 concludes.

\section{RECIPROCITY OF REASONS?}

As a first approximation, Forst's requirement of reciprocal and general acceptability takes a form like (for moral or political normative claims, $\varphi$ ):

RGA: $\varphi$ is justified, or valid, if and only if $\varphi$ is, or can be based on reasons that are, reciprocally and generally acceptable; $\varphi$ must be equally acceptable (reciprocity) by all affected people (generality). (See Forst 2012, 214; 2010, 711-40; 2014a.)

RGA is more complex normatively than its linguistic surface suggests. As we shall see, $\varphi$ counts as reciprocally and generally acceptable in RGA's sense just in case $\varphi$ is, or can be, based on "reasonably" nonrejectable reasons. I turn to this in Section 3, below. For now, let me take a look at RGA's notions of reciprocity and generality. As my focus is on reciprocity of reasons, I consider generality only briefly.

Generality refers to the scope of RGA's constituency: $\varphi$ is acceptable generally only if $\varphi$ is acceptable by all agents who are, or would be, relevantly affected by $\varphi$, its adoption, or its implementation. Forst leaves open

\footnotetext{
${ }^{4}$ See Besch $(2019 a, 471-73)$.
} 
how or on what grounds we may determine who counts as a "relevantly" 1 affected agent, and hence, how or on what grounds we can delineate RGA's 2 scope of inclusion. ${ }^{5}$ As I shall not take issue with this idea, however, I will 3 now set it aside.

Turning next to RGA's notion of reciprocity, then, Stefan Gosepath puts its upshot thus: "only that which is equally acceptable to everyone can be regarded as justified" (Gosepath 2015, 133). Forst himself tells us:

To be able to distinguish "acceptable" from "unacceptable" reasons, two criteria are required: reciprocity and generality. First, reasons that justify specific normative claims must be reciprocally non-rejectable, that is, the author of these claims may not demand any rights or privileges that he or she denies his or her addressee. Moreover, the author may not project her own opinions, interests or values onto others and thus decide for him- or herself, rather than reciprocally, how to fulfil the criterion of reciprocity. The same is the case for the addressee of the claims. (Forst 2012, 214.)

Reciprocity means that no one may make a normative claim... he or she denies to others (call that reciprocity of content) and that no one may simply project one's own perspective, values, interests, or needs onto others such that one claims to speak in their "true" interests or in the name of some truth beyond mutual justification (reciprocity of reasons). (Forst 2010, 719)

Reciprocal acceptability calls for reciprocity of content and of reasons. What does this mean? Reciprocity of content is relatively straightforward. Roughly, it requires claimants to treat like cases alike, and hence calls for a kind of (formal) impartiality. Let me set this aside as unproblematic.

Reciprocity of reasons is harder to pin down. ${ }^{6}$ To bring out the contours of this idea, I start by considering what the first of the above two passages tries to do. Forst elaborates on the kind of acceptability that RGA calls for. To this end, he draws on a contrast between deliberative resources - for example, interests, needs, views, volitions, capacities, and so on - that an agent actually has and resources that others (unduly, mistakenly) attribute to her. He suggests that for $\varphi$ to be "reciprocally acceptable" by an agent, she must be able to accept $\varphi$ in light of deliberative resources that she actually has. This suggests an actualist version of RGA:

RGA-a: $\varphi$ is justified, or valid, if and only if $\varphi$ is, or can be based on reasons that are, reciprocally and generally acceptable: $\varphi$ must be equally acceptable by all affected people from their actual perspective, or in light of their actual interests, needs, views, volitions, and so forth.

${ }^{5}$ On Forst's account of the scope of reciprocity and generality, see Erman (2014).

${ }^{6}$ As Benhabib notes, see Benhabib (2015, 782f.). 
Forst's writings often support an actualist interpretation of RGA, and many commentators read him in such terms. It is hence useful to highlight why we should not read RGA in actualist terms, if other terms are available (as, fortunately, they are: see next section). I start with a note on the (alleged) emancipatory or protective function of justifications that comply with RGA - a feature that seems to sit especially well with an actualist reading of RGA.

For Forst, RGA requires that agents be accorded a strong form of discursive standing - or a "high-purchase" form of discursive respect (Besch 2014, 2019a, 2019b). Justification practice that complies with RGA construes equal acceptability by actual agents as justifying. It hence situates them not as mere recipients, but as "equal participants and normative authorities" of justification (Forst 2017a, 134, 6ff; 2015a, 825; 2015b, 112). For Forst, this involves that agents be accorded a "qualified veto-right" that protects, or helps to protect, them from "unjustified domination" (Forst 2001, 168f; 2010, 719). It is only on the assumption that agents can make meaningful use of these veto-rights that Forst attributes to reciprocal and general justification an emancipatory or protective function. And it is on the assumption that such justification has this function that he takes a "basic structure" or reciprocal and general justification to enable many important things - such as proper respect for people's right to justification, fundamental justice, legitimacy, democracy, or political nondomination (Forst 2017a, 6f, $131-37)^{7}$

Now, to enable the emancipatory or protective function of reciprocal and general justification, Forst-type veto-rights must be relevantly accessible and authentic. Specifically, agents must be able to carry out what counts as a qualified, authoritative exercise of such rights (accessibility). And the authoritative exercise of these rights must relevantly track, or not distort, the agent's perspective (authenticity). For example, if justification recognizes rejections as authoritative exercises of Forst-type veto-rights only if they are ideally rational, average agents may be unable to authoritatively exercise them. And if their authoritative exercise asks agents to bracket, deny, or

\footnotetext{
${ }^{7}$ This can be simplified: there are two readings of Forst-type veto rights. On a weak reading, their authoritative exercise is conditioned by justification. For example, no rejection of $\varphi$ can be an authoritative exercise of a veto right if $\varphi$ is justified. On a strong reading, the authoritative exercise of these rights conditions justification. $\varphi$ here cannot count as justified if Betty rejects $\varphi$ in a manner that authoritatively exercises her veto right. I adopt a strong reading. It sits better with Forst's view that reciprocal and general justification situates agents as $a u$ thorities of justification. And it is foregrounded in his more recent work (see Forst 2017a, 1-21, 37-51, 131-51; Forst 2014a, 178-81, 187-200).
} 
idealize away commitments that they actually cannot detach from, they may be unable to make any meaningful use of these rights. ${ }^{8}$

Plainly, RGA-a is geared toward the desiderata of accessibility and authenticity (if these things are desiderata). This is so at least if we assume, in accordance with RGA-a's spirit, that an agent's rejection of $\varphi$ counts as an authoritative exercise of a Forst-type veto-right if she cannot coherently accept $\varphi$ from her actual perspective, or in light of her actual deliberative resources. Accordingly, Forst's writings suggest an actualist interpretation of RGA especially where he foregrounds the (putative) emancipatory or protective function of reciprocal and general justification.

However, if the requirement of reciprocal and general acceptability takes the form of RGA-a, then it is a nonstarter. RGA-a is inadequate as a standard of justification, or validity. Consider a principle that prohibits marital rape. If this requirement filters out such a principle as invalid, it cannot serve in the role of a standard of justification. But RGA-a would filter out this principle as invalid. As a matter of fact, some husbands are committed rapists: they take it to be their prerogative as husbands to force their spouses to have sex. Hence, some relevant agents cannot actually accept the principle in light of their actual deliberative resources. Thus, the principle violates RGA-a. A principle that permits marital rape would fare no different. You and I would be unable to accept the principle. Hence, marital rape would neither be prohibited nor permitted. As Uwe Steinhoff observes, similar results would follow for all relevantly contested normative content (Steinhoff 2015, 168). The general point is familiar and not specific for RGA-a: inclusive actualist "equal acceptability" justification leads to incoherence or anomy (Enoch 2015, 117f). ${ }^{9}$

\section{HYPOTHETICALIZED REGIPROCITY OF REASONS?}

There is more to RGA than RGA-a. Forst sometimes conceptualizes RGA in terms that call for hypotheticalized nonrejectability:

The defining feature of reasons that can justify moral claims is thus that they must be reasons that cannot be reasonably - that is, not reciprocally and generally - rejected. As such,

${ }^{8}$ I elaborate on accessibility and authenticity as components of an agent's normative influence in justification in Besch (2019a). One question that arises here is how low or high the idealization value of standards of acceptability-based justification must be in order to ensure that relevant levels of discursive influence (see Besch 2019b). See also Section 8, below. 9 Of course, if standards of justification, where they entail incoherence or anomy results, are incomplete, we might also say that inclusive actualist "equal acceptability" justification leads to incompleteness (see Gaus 1996, 151-58). 
they justify norms - and corresponding actions - that possess a morally unconditional normative character and are in a strict sense categorically binding as norms against whose validity no good reason can speak... This definition is stronger than the equally applicable but insufficient formulation that moral reasons must be "intersubjective," "comprehensible," "acceptable," "public," or "agent-neutral." It conforms to the idea that such reasons must be "shared" reasons, but accentuates the modal specification, that they must be sharable, in order to do justice to the openness of the procedure of justification and to underscore the (in this sense counterfactual) moment of reciprocal and general acceptability - or better, nonrejectability - independent of the factual acceptance or nonacceptance of reasons. (Forst 2012, 21)

This oscillates between an acceptance-focused and a rejection-focused reading of RGA, but Forst often prefers the latter. If we recall that RGA applies not only to moral claims, a reasonable nonrejectability version of RGA is suggested:

RGA-r: $\varphi$ is justified, or valid, if and only if $\varphi$ can be based on reasons "that cannot be reasonably - that is not reciprocally and generally - rejected."

According to RGA-r, what contributes to $\varphi$ 's justification status is not that relevant people can (cannot) accept $\varphi$ in light of their actual deliberative resources. Rather, what contributes to $\varphi$ 's justification status is that $\varphi$ can (cannot) be based on, or be accepted for, reasons that relevant people cannot reject reasonably.

RGA-r seems promising. RGA-r accommodates a need all standards of acceptability-based justification must accommodate. Acceptability can count toward justification only if it is, or counts as, suitably respectable, or authoritative. Thus, all standards of acceptability-based justification must somehow qualify the kind of acceptability that they construe as authoritative, or as positively contributing to justification. As RGA-r makes explicit, then, Forst's requirement of reciprocal and general acceptability adopts an idea of reasonableness in the role of a bar for (or criterion of) authoritativeness.

Next, building RGA on an idea of reasonableness can help to avoid incoherence or anomy results if the bar for reasonableness is put at a suitably demanding level. Of course, the more demanding that bar is relative to the deliberative resources of relevant claimants, the greater will be its tendency to attract controversies in its own right. This can put standards of justification that build on such bars in need of justification. And it is not obvious on what grounds or by what standards the justifications called for here could proceed. Still, in relation to incoherence or anomy results, RGA-r is potentially superior to RGA-a. 
Finally, RGA-r hypotheticalizes or idealizes (in one sense of the word). ${ }^{10} \quad 1$ But RGA-r still allows for accessibility and authenticity if its bar for reason- 2 ableness is defined in suitably accessible terms. Accessibility and authentic- 3 ity come in degrees, and reasonableness can be construed in more or less 4 demanding terms. Accordingly, the bar for a reasonable exercise of Forst- 5 $\begin{array}{ll}\text { type veto-rights can be placed at low enough levels to ensure that agents } & 6\end{array}$ can meet that bar and that "reasonable" exercises of these rights can track 7 their actual voices. Of course, the bar would still have to be set high enough 8 to avoid incoherence or anomy. It is not obvious what this calls for. Still, 9 that RGA-r hypotheticalizes is compatible with accessibility and 10 authenticity.

Assuming, then, that RGA takes the form of RGA-r, Forst effectively premises RGA on two additional views. First, he construes the authoritativeness of acceptability (or nonrejectability) in the following terms:

F1: $\varphi$ must be justifiable by reasons that no affected agent can reject reasonably.

Now, reasonable nonrejectability requirements like F1 are indeterminate so long as the idea of the reasonable they implicate remains unspecified. Thus, when are reasons "reasonably" nonrejectable in RGA-r's sense?

Unfortunately, Forst does not provide much in the way of an account of what makes normative claims "reasonably" nonrejectable. But a passage quoted earlier provides a clue. Here is it again (in shorted form):

The defining feature of reasons that can justify moral claims is thus that they must be reasons that cannot be reasonably that is, not reciprocally and generally - rejected.... This definition... conforms to the idea that such reasons must be "shared" reasons, but accentuates the modal specification, that they must be sharable, in order to... underscore the... moment of reciprocal and general acceptability - or better, nonrejectability. (Forst 2012, 21; first and last emphases added)

The defining feature of reasons that justify relevant claims is that they are "reasons that cannot be reasonably - that is, not reciprocally and generally - rejected." We may read the phrase between the dashes as specifying the phrase that it is embedded in. This is equally plain in the German original. Forst writes 31 there that the defining feature of the relevant reasons is "dass dies nicht vernünftigerweise - d.h. nicht reziprok-allgemein - zurückweisbare Gründe sein müssen" (Forst 2007, 36). "D.h." abbreviates "das heisst," which translates as "this means," or "that is to say." Thus, Forst tells us, the relevant reasons must be (2019b).

${ }^{10}$ On hypotheticalization as one form of idealization: see Enoch (2015) and Besch 
reasons that cannot be "reasonably" rejected and that is to say that they are reasons that cannot be "reciprocally and generally" rejected. This assumes that when (i), below, is true, then so is (ii) (for a relevant kind of reason, $\mathrm{R}$ ):

(i) R cannot be "reasonably" rejected.

(ii) R cannot be "reciprocally and generally" rejected.

Textual evidence suggests that Forst takes (ii) to define the meaning of (i). To elaborate on his usage of the phrase "reasonably nonrejectable," Forst stresses that while he takes the phrase from Scanlon, he "interpret[s]" it with his own criteria of reciprocity and generality in order to "more precisely define the meaning of "reasonable" than Scanlon did" (Forst 2012, 21, n. 38, and 272; emphasis added). ${ }^{11}$ This is in play when Forst more recently writes: "Adapting Thomas Scanlon's formulation ("not reasonable to reject"), I believe that moral justification requires that norms must rest on reasons that

3 are not reciprocally and generally rejectable." (Forst 2017, 28f.) This suggests:

F2: Reasons that cannot be rejected "reasonably" are reasons that cannot be rejected "reciprocally and generally," i.e., in a manner that meets the requirement of reciprocal and general acceptability.

We just encountered textual evidence that Forst not only adopts F2, but also takes F2 to register what defines the meaning of claims like "Reason R is reasonably nonrejectable." My subsequent argument does not hinge on this further view. I shall simply assume that Forst adopts F2 so that, in his framework, reasons are not "reasonably" nonrejectable unless they are "reciprocally and generally" nonrejectable.

Some comments are in place. First, we saw earlier that standards of acceptability-based justification must qualify the kind of acceptability that they construe as authoritative, or as contributing to justification. Over the years, Forst grappled with the issue - which reflects in RGA's ambiguity between RGA-a and RGA-r. Since his early work on the theme, he construes "moral" (as opposed to more limited "ethical") ${ }^{12}$ justifications in strong universalist terms as requiring justifiers, or reasons, that are reciprocally acceptable as justifiers, or as reasons, by all affected others: reasons, he insists, are "good moral reasons" only if they themselves meet the criteria of reciprocity and generality, while no "conviction" that does not meet this test can raise moral validity claims (Forst 2002, 39). ${ }^{13}$ This presents Forst

\footnotetext{
11 Forst refers to Scanlon (1982).

12 See Forst (2012, 62-78).

13 The German version of the text quoted from here is Forst (1994).
} 
with the challenge to adopt authoritativeness constraints on the acceptability of justifiers, or reasons, that, without undermining his constructivism, allow him to remain faithful to his universalist aspirations and to avoid idealizations that undermine the (putative) emancipatory or protective role of moral justification. This is where he reaches for F2. He looks to Scanlon for a reasonableness constraint on the acceptability of justifiers that actual people can actually meet. But he then interprets this constraint in light of his view that justifiers provide "moral" justification only if they meet the requirement of reciprocity and generality. And so "reasonable" nonrejectability becomes "reciprocally and generally" nonrejectability.

Yet, second, F2 is problematic. If claims satisfy RGA-r only if they can be based on reasons that are "reasonably" nonrejectable, but reasons are "reasonably" nonrejectable only if they are "reciprocally and generally" nonrejectable, that is, in a manner that satisfies RGA-r, something seems amiss. Forst seems to construe a practice that abides by F2 as a reflexive practice of reason-giving in which all normative claims - including claims like " $\varphi$ is (not) reasonably nonrejectable" - can at any time be called into question and may be upheld only if they meet the requirement of reciprocity and generality. But if we adhere to RGA-r and interpret it in terms of F2, we can never tell whether normative claims pass that test (see Sections 5 and 6).

Hence, third, it is worth highlighting that the conjunct of RGA-r and F1 by itself does not commit us to F2. We can accept RGA-r and adopt a reasonable nonrejectability view of reciprocal and general acceptability, while we reject the claim that "reasonably" nonrejectable reasons must be "reciprocally and generally" nonrejectable reasons. As I argue below, this is what we should do if we wish to adopt RGA-r and F1. And this would open up space to engage on substantive grounds - for example, grounds that elevate the importance of the emancipatory or protective role of moral justification - what reasonableness constraint, if any, an acceptability-based justification should adopt (see Section 8). (Readers who wish to deny that Forst adopts F2 are free to read the following discussion in conditional terms: the argument is that if Forst adopts F2, then his view runs into problems, so that he has reason not to adopt F2 and to embrace the advocated conclusion.)

\section{A DUTY OF JUSTIFICATION?}

Can RGA-r serve as a standard of justification in engaged discursive practice? Do we have a duty of justification to meet RGA-r? I turn to this in Section 5. For now, I confirm that Forst attributes to us such a duty and address two concerns that arise here. 
To start with, for Forst, the requirement of reciprocal and general acceptability is to apply to discursive practice from the inside, or from the first-person perspective of normatively engaged participants. For Forst, "the only perspective to which we have access is that of a participant, not one of a trans-historical observer" of practices or reason giving or justification (Forst 2017a, 6). It is as discursively engaged participants that we have an "unconditional duty" (Forst 2012, 21) to justify, or be able to justify, ourselves to others in accordance with a reasonably nonrejectable "principle of justification" (18)-Forst calls it "the principle of reason" (Forst 2017a, 6) - according to which all claims must be "justified in precisely the manner referred to by their validity claims" (Forst 2012, 18, 21, 27, 66f, 249, 259; 2017a, 3f). Given Forst's view that moral or political claims raise validity claims such that these claims depend for their justification, or validity, on their reciprocal and general acceptability, ${ }^{14}$ he thereby attributes to us a duty to justify, or be able to justify, ourselves, or salient claims of ours, to others on grounds that meet RGA-r.

Moreover, Forst claims that we take that ourselves and others can access and navigate "an intersubjective space of justifying reasons" (Forst 2012, 27) - a capacity that we exercise by justifying our claims to others on grounds that meet RGA-r. Writes Forst:

If one does not make this assumption, it would be a form of disrespect: one would not be respecting the other as an autonomous moral person if one did not expect her to be able to justify her actions with reasons that cannot be reciprocally and generally rejected, with reasons that are intersubjectively available. One would then be viewing the other primarily as an object of explanation, not as a subject of justification. (18f.)

Thus, we have a duty to (be able to) justify ourselves to others in accordance with RGA-r; and we take each other to be able to meet this duty.

It is helpful to contrast Forst's view of a duty of justification with other possible views. We might think of such a duty in various ways, for example, as:

1. a duty that salient claims be justifiable (call this a duty of justification in the widest sense: the duty leaves open what justifiability requires);

2. a duty that salient claims be justifiable to others (call this an interpersonal wide duty of justification: it requires interpersonal justifiability, but leaves open what this calls for);

14 I engage and reject this view in Besch (2015). 
3. a duty that salient claims be justifiable to others on grounds that are reasonably nonrejectable (call this as an interpersonal strong duty of justification: it requires interpersonal justifiability on grounds that meet the demanding, or strong, condition of being "reasonably nonrejectable");

4. a duty that salient claims be justifiable to others on grounds that are reasonably nonrejectable in RGA-r's sense (call this as a interpersonal narrow duty of justification: it requires interpersonal justifiability on grounds that are "reasonably nonrejectable" specifically, or narrowly, in RGA-r's sense).

Forst's duty of justification is a duty of type-(4)-justification. Moreover, Forst often refers to this duty in terms such that it requires for its fulfilment performances of justification or actual reason giving. Two concerns arise.

First, it is doubtful that a reasonably nonrejectable duty of justification can take the form of a duty of type-(4)-justification. Other things being equal, any duty of justification the content of which is given by, or depends on, a contested conception, or doctrine, of moral or political justificationsay, any doctrine-dependent duty of justification - is likely to be as contested as the doctrine that supplies its content. Hence, if a duty of justification is to be reasonably nonrejectable, there are reasons to construe in doctrinally neutral terms - terms that abstract from, and are neutral toward, conceptions of justification that reasonable people reasonably disagree about. ${ }^{15}$ But a Forst-type duty of justification is not neutral in this sense. It is indexed to a reasonably contested, constructivist view of justification. ${ }^{16}$

Second, any performance duty of justification is at least morally conditioned in application, and trivially so. Reason giving is activity. But what course of action is morally called for in a given situation depends on what is morally at stake in that situation. For example, if your choice is between saving lives and giving reasons, you should save lives. The point: it can be unreasonable not to give others reasons only if there is opportunity to do so and trumping countervailing considerations are absent.

And even if circumstances otherwise allow for it, reason giving is not always a proper response to discursive challenges. As Aristotle notes,

you ought not to discuss with everybody... for with some people argument is sure to deteriorate; for with a man who appears to try every means to escape from the

15 This uses O'Neill's notion of abstraction (see O'Neill 1996, 38-44; 1988a). One upshot of abstraction in this sense is that if a claim $\alpha$ is abstracted from two conflicting claims, $\beta$ and $\gamma$, then $\beta$ and $\gamma$ each entail $\alpha$, while $\alpha$ does not commit to $\beta$ or to $\gamma$, and hence is neutral between them.

${ }^{16}$ I assume throughout that anticonstructivism can be reasonable, and that RGA is the subject of reasonable disagreement (see Besch 2015). 
right [conclusion] you are justified in trying everything to come to such a conclusion; however, this is not a seemly proceeding.... [It] can only result in a debased kind of discussion. ${ }^{17}$

It is not unreasonable for us not to give reasons if others are culpably unwilling to be duly responsive to relevant discursive efforts of ours. Another salient situation type concerns unreasonable rejection grounds. Where rejections are based on such grounds, they do not, or not always, put reasonable views in need of justification. And in such cases, it is not, or not always, unreasonable not to respond to rejections by giving reasons (e.g., consider openly racist denials of the view that everyone is owed moral concern). And there are many other situation types in which it is not unreasonable not to respond to discursive challenges with reason giving.

What to make of this? We can set aside the second concern. On a charitable reading, a duty of type-(4)-justification requires justifiability and calls for performances of justification only if suitable conditions obtain. This is plausible, and it is how I read Forst here.

The first concern raises deeper issues. One reply is this. Yes, a duty of type-(4)-justification is reasonably contested. But we can have this duty even if the claim that we do is not equally acceptable by all relevant people. And while this reply seems plausible, it seems unavailable for Forst. Note first 4 that he often applies RGA to all normative claims (Forst 2015, 214; 2017a, $1-36)$. Yet the claim that we have a duty of type-(4)-justification is a normative claim. Thus, this claim, too, would depend for its justification, or validity, on its reciprocal and general acceptability. Now, Forst also assumes that if there is reasonable disagreement about $\varphi$, then $\varphi$ is not reciprocally acceptable by the people who reasonably disagree about $\varphi \cdot{ }^{18}$ But there is reasonable disagreement about the claim that we have a duty to type-(4)-justification. Hence, this claim would not be justified, or valid. Finally, in Forst's constructivist framework, if "we ought to $\varphi$ " is not valid, then it is not the case that we ought to $\varphi$. Thus, we would not have a duty to type-(4)-justification.

Various rejoinders are possible. For example, maybe the claim that we have a duty of type-(4)-justification need not be reciprocally and generally acceptable; or maybe disagreement about this claim is not reasonable, or does not rule out the claim's reciprocal and general acceptability; or maybe a duty of type-(4)-justification applies to us even if the claim that it does

\footnotetext{
17 This is Postema's translation of Topics 164b8-14 (see Postema 1995, 356).

${ }^{18}$ Forst puts this view to important use in his account of the criterion of respect toleration (see Forst 2003a, 2003b, 588-649).
} 
is not valid in RGA's sense. However, none of this sits well with Forst's constructivism. But let us set this aside and take away just two things. It is doubtful that a reasonably nonrejectable duty of justification takes the form of a duty to type-(4)-justification. And a duty of justification, if we have one, primarily requires justifiability.

\section{RGA-R: A REGRESS PROBLEM}

Can RGA-r serve as a requirement of justification, or validity, in engaged discursive practice? I shall now suggest that this is not so.

Suppose that you try to find out whether a given normative claim (or view, opinion, etc.) of yours, $\varphi 1$, is justifiable, or valid, in RGA's sense. This task is more complex than it might initially seem. RGA does not take the actualist form of RGA-a, but the hypotheticalized form of RGA-r. Accordingly, it is not enough for you to determine whether there are relevant people who can or cannot actually reject $\varphi 1$, or who can, could, or are committed to reject $\varphi 1$ on grounds that, by their lights or by yours, are plausible, respectable, good, or compelling. Instead, you must determine whether $\varphi 1$ can be based on, or be accepted for, reasons that are "reasonably" nonrejectable. And these reasons must be "reasonably" nonrejectable in not just any sense of the notion, but in F2's sense: they must be reciprocally and generally nonrejectable. Thus, what must you do in order to determine whether $\varphi 1$ can be based on, or be accepted for, such reasons?

Unfortunately, Forst is not helpful here. He refers to reasons as reciprocally and generally nonrejectable, but he does not explain what this says about them - other than that these reasons cannot be rejected on grounds that meet RGA-r. But if this is what we must go by - as apparently we must - problems loom. Why?

Recall first that you are trying to determine whether $\varphi 1$ can be based on, or be accepted for, reasons that are "reasonably" nonrejectable in F2's sense. Let " $\varphi 2$ " refer to an actual or possible candidate reason that you are tempted to bring in here. For instance, $\varphi 2$ might be persuasive from your perspective, or respectable peers of yours might report that they accept $\varphi 1$ on grounds of $\varphi 2$. What you need to determine, then, is whether the normative claim " $\varphi 2$ is a reason for $\varphi 1$ " can be rejected on the basis of reasons that meet RGA.

Of course, by itself, it makes good sense to examine whether there are good reasons to reject the normative claim " $\varphi 2$ is a reason for $\varphi 1$ "- for brevity's sake, let me refer to this claim as " $\varphi 3$." One salient issue here is whether there are relevant normative considerations that undercut $\varphi 2$ 's 
role as a reason for $\varphi 1$. And, it would seem, it is plausible to claim that normative considerations can serve as such undercutters only if these considerations themselves are authoritative in some salient sense. And for Forst, this requires that they meet RGA-r.

But then things get murky. For what you need to do now is to determine whether $\varphi 3$ can be rejected on grounds that meet RGA-r. As before: to determine this, it is not enough to find out whether there are relevant people who can or could - or are committed to - reject $\varphi 3$ for reasons that, by your lights or by theirs, are plausible, respectable, good, or compelling. No actual or possible rejection of $\varphi 3$ counts toward your task unless it can be based on reasons that meet RGA-r. Let " $\varphi 4$ " refer to a candidate reason to reject $\varphi 3$. Your question hence becomes whether $\varphi 4$ is a rejection reason that meets RGA-r.

Again, to answer this question, you must determine whether the claim " $\varphi 4$ is a reason to reject $\varphi 3$ " can be rejected on the basis of reasons that meet RGA-r. And this leaves you in the same doxastic predicament that you were in when you considered $\varphi 3$. Refer to the claim " $\varphi 4$ is a reason to reject $\varphi 3$ " as " $\varphi 5$ " and let " $\varphi 6$ " refer to a candidate reason to reject $\varphi 5$. Accordingly, you now need to determine whether the normative claim " $\varphi 6$ is a reason to reject $\varphi 5$ " can be rejected on grounds that meet RGA-r. And at least as far as RGA-r is concerned, you may not stop here.

This looks like a viciously regressive structure. RGA-r counts normative claims as justified, or valid, only if they can be based on reasons that cannot authoritatively or reasonably be rejected. But RGA-r in effect construes the reasonableness of rejections in terms such that

(i) at any stage or level of deliberation, RGA-r counts rejections as reasonable only depending on whether they are, or can be, based on respectable reasons;

(ii) at any stage or level of deliberation, RGA-r counts actual or possible rejection reasons as respectable only depending on whether there are, or can be, reasonable rejections of their role as such reasons.

This is regressive since we cannot determine the reasonableness of any given, actual, or possible rejection of $\varphi i$ without first determining whether there are, or can be, reasonable rejections of the reasons that this rejection is, or can be, based on - while RGA-r does not provide any additional, suitably determinate notion of the reasonableness of rejections. And this is vicious, in turn, because it makes us unable to identify whether normative claims are justified, or valid, in RGA-r's sense. 
The point: if RGA-r is all that we go by, then no normative claim can be, or be known to be, justified, or valid. Hence, RGA-r cannot serve as a requirement of justification for engaged discursive practice. Saying this does not deny that validity can be construed as a property that claims have, or fail to have, even if no actual agent can identify that this is so ${ }^{19}$ But RGAr's designated role is to serve as a standard of justification, or validity, for actual agents in their engaged discursive practice. But RGA-r cannot serve as such a standard if no actual agent can identify when salient claims meet RGA-r.

\section{TWO COMMENTS}

First, let us distinguish RGA-r's regressive character from its role in Forst's dynamic view of interpersonal reasoning and justification. We have seen that Forst sometimes applies RGA to all normative claims. He conceptualizes this in terms of a potentially open-ended process of inclusive and reflexive (or "recursive") interpersonal reasoning and justification that is constrained by RGA and that does not exempt any subset of normative claims from this requirement. On this view, any one normative claim is justified, or valid, only if its putative justifiers meet RGA. And any one normative claim, including justifiers of other claims, can be called into question, or be put in need of justification, while all normative claims depend for their justification, or validity, on meeting RGA. And as agents are often unable to anticipate all relevant objections that other agents might raise, 5 validity claims must often be provisional (Forst 2012, 155-87; 2017, 21-35). Fair enough. Validity claims are often provisional, and perhaps they are best construed as claims like "Given currently available relevant evidence, $\varphi$ meets validity condition C." But RGA-r's problem is not that we do not know enough to tell when claims meet the relevant validity condition. The problem is that we cannot know when that condition is met. Contrast (i) being able to identify (that is, in principle) when validity condition $\mathrm{C}$ is met and not knowing whether $\mathrm{C}$ is met, and (ii) being unable to identify (that is, in principle) when $\mathrm{C}$ is met and hence never knowing whether $\mathrm{C}$ is met. RGA-r leaves us in a situation like (ii). If the provisionality of validity claims in practices of reasoning and justification reflects (i), it might reflect a merit - for example, the moral merit of respecting every relevant person as an equal coauthor of justification, or the epistemic merit of open-mindedness and corrigibility.

${ }^{19}$ For example, Wall's view of public justification construes validity in such terms (see Wall 2016, 207ff, 215-20). 
But if it reflects (ii), it reflects a deficiency. Discursive practices that follow standards that make it impossible to identify when salient claims are justified can hardly be practices of justification.

For a second comment, consider a self-suggesting attempt to rescue RGA-r. If we build more content into it, RGA-r might not be viciously regressive. And Forst concedes that more content may be added to the requirement so long as this content, or adding it to RGA-r, "fulfil[s] the criterion of reciprocity [and generality]" (Forst 2012, 214). For the sake of argument, I now grant that there are predicates, $\alpha$, such that building $\alpha$ into RGA-r allows the then-enriched requirement, $\alpha \mathrm{RGA}-\mathrm{r}$, to avoid the regress problem (e.g., consider elements of Rawls-type reasonablenessmaybe RGA-r is not regressive if it counts reasons as reasonably nonrejectable only if they cohere with liberal values). ${ }^{20}$ Might this help?

One way to pick up the stick is to consider what it takes for RGA-r to constrain attempts to enrich RGA-r's content. RGA-r can be such a constraint only if the requirement is available in a form that allows it to do, well, relevant constraining - that is, a form that enables us to tell whether $\alpha$, or building $\alpha$ into RGA-r, is reciprocally and generally acceptable. But the problem just is that RGA-r is not available in such a form. The regress problem arises because we cannot tell when anything meets the requirement. Hence, the problem that we try to remedy by adding $\alpha$ to RGA-r will reappear when we examine whether we may add $\alpha$ to RGA-r. By implication, claims to the effect that it is reciprocally and generally acceptable to build $\alpha$ into RGA-r would have to be stipulative, arbitrary or dogmatic.

This conclusion is hasty. When we ask whether adding $\alpha$ to RGA-r is reciprocally and generally acceptable, we might test for either of two things:

1. Does adding $\alpha$ to RGA-r meet RGA-r? (This tests, say, simple reflexivity.)

2. Does adding $\alpha$ to RGA-r meet $\alpha R G A-r$ ? (This tests, say, enriched reflexivity.)

The problem just pointed out occurs if we answer (1): any regressive tendency in RGA-r will trouble us again when we examine whether adding $\alpha$ to RGA-r meets RGA-r. But things might be different if we answer (2): the then-enriched requirement might not be regressive. Can a test of enriched reflexivity help?

It is not clear what kind of merit enriched reflexivity is, if any. But even if $\alpha$ is such that $\alpha$ RGA-r is not regressive and building $\alpha$ into RGA-r is

\footnotetext{
${ }^{20}$ See Lister (2017, 158); see also Besch (2012).
} 
reciprocally and generally acceptable in terms of $\alpha$ RGA-r, it does not follow that we may add $\alpha$ to RGA-r, or that $\alpha$ RGA-r may serve as a standard of justification, or validity. To see why, consider fundamentalist variants of reciprocity and generality - which satisfy enriched reflexivity, but for the wrong reasons.

To simplify slightly: according to RGA-r, $\varphi$ is justified if and only if $\varphi$ can be based on "reasonably" nonrejectable reasons. Suppose, then, that we consider enriching RGA-r's content by defining "reasonably" nonrejectable reasons as reasons \{that are nonrejectable for right-minded people, that is, people who always give highest priority to True Doctrine\}. Let the bracketed part of this sentence be a candidate predicate $\alpha^{*}$. Our task then becomes to see whether building $\alpha^{*}$ into RGA-r meets $\alpha^{*}$ RGA-r. Presumably, this asks us to consider something like:

Q1: Can the claim " $\varphi$ is justified if and only if $\varphi$ can be based on reasons that are non-rejectable from the perspective of right-minded people, i.e., people who always give highest priority to True Doctrine" be based on reasons that are non-rejectable from the perspective of right-minded people who always give highest priority to True Doctrine?

Plainly, the answer to Q1 depends on the contents of True Doctrine - rather than, for example, on what all affected people can or cannot accept or reject. And we may conjecture that this answer will be in the affirmative so long as True Doctrine is exclusionary enough so as to not require nonrejectability from the perspective of anyone other than people who give highest priority to True Doctrine. But if $\alpha^{*}$ RGA-r is self-selective for this reason, this cannot recommend $\alpha *$ RGA-r, or at least not so long as we do not have prior, independent reasons to privilege the contents of True Doctrine.

The upshot: even if $\alpha *$ RGA-r satisfies enriched reflexivity, it does not follow that $\alpha *$ RGA-r may serve as a standard of justification. That a candidate standard of justification satisfies enriched reflexivity does not recommend the standard unless the reason why it does this is meritorious. And this it might not be as the example of fundamentalist reciprocity and generality illustrates. Thus, even if enriching RGA-r's content could render RGA-r nonregressive, subjecting the then-enriched standard to a test of reflexivity either brings back the regress problem, or does not accomplish enough. ${ }^{21}$

${ }^{21}$ Note that the problem at hand is distinct from a problem of self-defeat that is often attributed to Rawls's view of public justification. The latter is a problem such that (i) Rawls's claim that political things of a certain kind must be publicly justifiable itself is a political thing of that kind, but, prior to further argument, (ii) this claim is not publicly justifiable (see Estlund 1998, 257; Raz 1998; Besch 1998, chap. 1; Wall 2002). Forst's problem is different: we cannot know whether RGA-r fails or passes its own test in simple reflexivity; and if RGA-r passes its own test in enriched reflexivity, this does not accomplish enough. I am indebted to an anonymous reviewer for reasons to highlight this here. 


\section{A DUTY OF TYPE-(4)-JUSTIFICATION?}

Do we have a duty of type-(4)-justification? The above suggests No Duty $(\mathrm{ND})$ :

ND: If we have a duty of type-(4)-justification, we would be under a duty to be able to justify ourselves, or salient claims, to others on grounds that are reasonably nonrejectable in RGA-r's sense. But as there cannot be a duty to comply with a viciously regressive standard, we do not have a duty to type-(4)-justification.

The target here is the view that we have a duty to meet $R G A-r$. ND does not deny that we have a duty of justification in any of the other senses referred to in Section 4 above.

Let me consider briefly why there is no duty to meet a viciously regressive standard like RGA-r. One reason (though presumably not the only one) is this: such a duty cannot be agent transparent or be intelligible and adopt$a b l e^{22}$ for the agent. To simplify: when we take a duty like "You ought to $\varphi$ " to apply to us, we normally take it not only that we $\operatorname{can} \varphi$ (in a salient sense of "can"), but also that we are in the position to know, or can know (in a salient sense of "can know"), what constitutes ping. Accordingly, if others are nonculpably unable to know, or come to know, what a duty prescribes - that is, if the duty is nonculpably unintelligible to them - we do not take the duty to apply, or regard noncompliance not as blameworthy, other things being equal. This heralds that we adopt a presumption of agent transparency: we assume that duties and agents are such that when a duty applies to an agent, so that it would be blameworthy for the agent not to comply with it, then the duty is intelligible to the agent, other things being equal.

However, for a duty to be agent transparent in the right way, a conception of what the duty prescribes must be accessible by the agent that can provide some level of orientation or constrain her judgment as to what to do. For example, Betty's noncompliance with "You ought to do the right thing!" is not blameworthy if "the right thing" is defined as "what does the trick," but no information whatsoever is accessible as to what does the trick. There is still a notional sense in which Betty can know what the duty prescribes: she knows that what she is to bring about is what does the trick. But, by hypothesis, the descriptor is entirely uninformative, and hence Betty cannot fix its reference. But since she cannot do this, the duty does not map

22 This follows O'Neill. For O'Neill, practical thought is reasoned or reasonable only if it is intelligible and adoptable - or followable "in thought" and "in action" (see O'Neill 1996, $51-65 ; 1988 b)$. 
onto her choice or constrain her judgment as to what to do. Thus, the duty is not adoptable by her. At the very least, then, her noncompliance is not blameworthy.

A duty to meet RGA-r leaves us in a situation like Betty's, but with a twist. In a notional sense, RGA-r allows us to know when salient claims are valid: they are valid when they can be based on reasons that cannot reciprocally and generally be rejected. But as RGA-r is viciously regressive, we cannot get a fix on the reference of the descriptor and so it does not map onto our choice. But the descriptor is not just indeterminate. Rather, it is amphibolic: we know that when we do fix its reference, this will involve stipulation, arbitrariness, or dogmatism, and hence something that is not sanctioned by RGA-r. However, if we cannot (permissibly) sort claims into those that this descriptor refers to and other claims, then we cannot (permissibly) sort claims into those that are "justified" or "valid" and those that are not. Thus, a duty to meet RGA-r is not agent transparent and not adoptable. But its failure to be these things is not owed to agent imperfection or agent limitation. RGA-r is viciously regressive: there is no salient level of agent perfection or agent idealization at which the duty becomes transparent and adoptable - or at least we, real people, are unable to identify whatever level this might be.

\section{WHAT DOES THIS GALL FOR?}

This leaves us with many possibilities. The core of the problem at hand is not (i) the view that relevant claims must be reciprocally and generally acceptable, or (ii) that this requirement must be understood in terms of RGA-r, or (iii) that RGA-r must pass its own test. The core of the problem is that RGA-r understands reasonableness in terms of F2. We may be able to avoid this problem and endorse (i)-(iii) if RGA-r understands reasonableness in different terms. This casts the door open for other ideas of the reasonable. What idea of reasonableness (if any) may reciprocal and general justifications draw on?

Let me elaborate on a particularly vexing aspect of this matter - one that goes to the heart of the (putative) emancipatory or protective function of reciprocal and general justification. We saw earlier that in order to serve this function, justification practice must accord agents a relevant measure of discursive influence in justification or on its outcomes. Forst tries to capture this by claiming that reciprocal and general justification accords people qualified veto-rights. But allocating such rights per se means little unless people can use them to exert a relevant level or measure of discursive influence. 
But what level is that? And what else must be true of justification practice for people to be able to make meaningful use of their veto-rights? in terms that are high in idealization value, people can be left with little discursive influence. For example, if it recognizes Paul's rejection of $\varphi$ as a suitably qualified, authoritative exercise of a discursive veto-right only if Paul's rejection of $\varphi$ instantiates ideal levels of (epistemic or moral) reasonableness, then actual Paul, given his actual limitations, might be unable to authoritatively exercise his veto-right. But if his rejection of $\varphi$ needs only to instantiate average levels of reasonableness, Paul might be able to authoritatively exercise his veto-right and make protective or emancipatory use of it. The point: reciprocal and general justification can serve an emancipatory or protective function only if a relevant bar for authoritativeness is set low enough to make it a readily accessible option for people to authoritatively reject views that they are actually committed to reject. ${ }^{23}$

But this leaves us in a tight spot. If we construe reciprocal and general acceptability in RGA-r's reasonable nonrejectability terms and set RGA-r's bar for reasonableness low enough so that relevant people, or their rejections, can meet that bar, then we bend RGA-r in an actualist direction. Now reciprocal and general justification must also model discursive equality: it aspires to treat all affected agents as equal authorities of justification. But the lower RGA-r's bar for reasonableness is set relative to the deliberative resources of actual people, the less will the resulting, actualist form of reciprocal and general justification be able to avoid incoherence or anomy results of the sort that disqualified RGA-a (see Section 3). ${ }^{24}$ The upshot: if RGA-r is to serve as a standard of justification - rather than a nonjustificatory constraint on public will-formation - the emancipatory or protective aspirations of reciprocal and general justification sit uneasily with its egalitarian commitments.

This is not the place to explore how reciprocal and general justification might construe discursive equality to reconcile it with its emancipatory or protective commitments (I do so elsewhere). ${ }^{25}$ But it is plain that this reconciliation task is of the essence where a conception of justification sets itself the task to work out the idea of a "social order that is both historically possible and normatively justified" (Forst 2017a, 1) and that accords to each

\footnotetext{
${ }^{23}$ On the relationship between idealization and discursive influence: see n. 8, above, and Besch (2019b).

24 This problem is not distinctive for Forst's RGA. For an account of the problem in Rawls's political liberalism, see Enoch (2015).

${ }^{25}$ See Besch (2019a, 2019b).
} 
relevant person a share of the power of justification or meaningful rejection rights that (help to) protect them from "unjustified domination" (Forst 2001, 168f).

This reconciliation task calls for considerations beyond RGA-r's purview. It calls for a calibration of RGA-r's bar for authoritativeness, which is part of what determines RGA-r's meaning and normativity. And this task is substantive. Amongst other things, this calibration must be done in light of some view of the importance of an agent's having, or being accorded by others, discursive influence. It calls for a comparison of the merits of candidate allocations of such influence across relevant constituencies. And it must be done in light of a view about how the respective merits of such allocations measure up against other goals or values that justification practice stands to serve. Thus, what level of discursive influence in justification should relevant agents be able to exercise? What level is needed, or desirable? And if unequal allocations of discursive influence are unavoidable, when are they permissible, or just? ${ }^{26}$

Unless such questions can plausibly be answered, we do not know how RGA-r's bar for authoritativeness may be calibrated. And if we do not know this, we do not know whether the fact that $\varphi$ meets RGA-r confers authority on $\varphi$. After all, it cannot both be true (i) that $\varphi$ is justified in virtue of meeting a (putative) standard of acceptability-based justification such as RGA-r and (ii) that this standard impermissibly allocates discursive influence. Thus, the substantive questions just referred to are more fundamental in the order of justification than RGA-r, or (putative) justifications by this standard.

I examined Forst's view of reciprocal and general acceptability with a focus on reciprocity of reasons. On an initially promising reading, RGA calls for reasonable nonrejectability. RGA-r might avoid incoherence or anomy results, and it is not incompatible with the desiderata of accessibility and

${ }^{26}$ To explore these issues further, Besch (2019a) considers views of the permissibility of purchase inequality, or conceptions of purchase justice, while Besch (2019b) argues that justification practice should set the idealization value of its bar for authoritativeness low enough to make it a genuinely available option for relevant people to reject salient claims in ways that, within that practice, count as authoritative. This caps the idealization value of standards of justification and it defines a minimum level of discursive purchase. Where justification practice meets this standard, it recognizes relevant people as "self-authenticating sources of valid claims" (Rawls 2001, 23) and allocates them the recognitive discursive minimum (Besch 2019b). I am indebted to an anonymous reviewer for reasons to highlight this here. 
authenticity. But even setting aside doubts as to whether a reasonably nonrejectable duty of justification can take the form of a duty to type-(4)-justification, Forst's conception of reciprocity of reasons fails. RGA-r is viciously regressive. And a duty of justification to meet RGA-r is not agent transparent and adoptable. The upshot: perhaps there are standards of justification, or validity, such that if discursive practice complies with them, such practice serves salient emancipatory or protective aims. But RGA-r does not seem to be one of these standards.

To salvage RGA-r and the idea of a duty to justification, we must reinterpret these things in light of an idea of the reasonable that we may adopt. Accordingly, we have reasons to construe of RGA-r's normative content itself as something that calls for justification. Thus, we should downgrade RGA-r in the order of justification and calibrate RGA-r, or its content, in light of substantive views about the measure or level of discursive influence that relevant people should be able to exercise in justification, given salient emancipatory and egalitarian commitments.

It is not clear what this call for and whether it can be accomplished in terms that are widely shareable by relevant agents. But it is clear that this matter must be addressed to salvage RGA-r and the view that we have a duty of justification to meet this requirement.

\section{REFERENCES}

6 Alan, Amy. 2014. "The Power of Justification." In Fustice, Democracy and the Right to 7 Fustification, edited by R. Forst. London: Bloomsbury Publishing.

Benhabib, Seyla. 2015. "The Uses and Abuses of Kantian Rigorism. On Rainer Forst's Moral and Political Philosophy." Political Theory 43, no. 6: 778-92.

Besch, Thomas M. 1998. Über John Rawls's politischen Liberalismus. Frankfurt am Main: Peter Lang.

- 2012. "Political Liberalism, the Internal Conception, and the Problem of Public Dogma." Philosophy and Public Issues 2, no. 1: 153-77.

- 2014. "On Discursive Respect." Social Theory and Practice 40: 207-31.

- 2015. "On the Right to Justification and Discursive Respect." Dialogue: Canadian Philosophical Review 54, no. 4: 703-26.

- 2019a. "On Robust Discursive Equality." Dialogue: Canadian Philosophical Reviere 58, no. 3: 465-90.

- 2019b. "On Justification, Idealization, and Discursive Purchase." Philosophia 47, no. 3: $601-23$.

Erman, Eva. 2014. "The Boundary Problem and the Right to Justification." In Fustice, Democracy and the Right to Fustification, edited by Rainer Forst, 127-46. London: Bloomsbury Academic. 
Enoch, David. 2015. "Against Public Reason." In Oxford Studies in Political Philosophy, edited by D. Sobel, P. Vallentyne, and S. Wall, Vol. 1, 112-44. Oxford: Oxford University Press.

Estlund, David. 1998. "The Insularity of the Reasonable: Why Political Liberalism Must Admit the Truth." Ethics 108, no. 2: 252-75.

Forst, Rainer. 1994. Kontexte der Gerechtigkeit. Frankfurt am Main: Suhrkamp. . 2001. "Toward a Critical Theory of Transnational Justice." Metaphilosophy 32, no. 1/2: 160-79.

2002. Contexts of Fustice. Berkeley: University of California Press.

2003a. Toleranz im Konflikt. Frankfurt am Main: Suhrkamp.

2003b. Toleration, Justice and Reason. In The Culture of Toleration in Diverse

Societies, edited by C. McKinnon and D. Castiglione, 71-85. Manchester: Manchester

University Press.

- 2007. Das Recht auf Rechtfertigung. Frankfurt am Main: Suhrkamp.

. 2010. "The Justification of Human Rights and the Basic Right to Justification:

A Reflexive Approach." Ethics, 120, no. 4: 711-40.

- 2012. The Right to Fustification. New York: Golumbia University Press.

2014a. "Justifying Justification: Reply to My Critics." In Justice, Democracy and

8 the Right to Fustification, 169-216. London: Bloomsbury Academic.

- 2014b. Fustification and Critique. Cambridge: Polity Press.

. 2015a. "The Right to Justification: Moral and Political, Transcendental and

Historical Reply to Seyla Benhabib, Jeffrey Flynn and Matthias Fritsch." Political

Theory 43, no. 6: 822-37.

_ 2015b. "Noumenal Power." The Fournal of Political Philosophy 23, no. 2: 111-27.

2016. "The Point and Ground of Human Rights: A Kantian Constructivist

View." In Global Political Theory, edited by D. Held and P. Maffettone, 22-39.

Cambridge: Polity Press.

- 2017a. Normativity and Power. Oxford: Oxford University Press.

- 2017b. "Political Liberalism: A Kantian View." Ethics 128, no. 1: 123-44.

Gaus, Gerald. 1996. Fustificatory Liberalism. Oxford: Oxford University Press.

Gosepath, Stefan. 2015. "On the (Re)Construction and Basic Concepts of the Morality of Equal Respect." In Do All Persons Have Equal Moral Worth?, edited by U. Steinhoff, 124-41. Oxford: Oxford University Press.

Laden, Anthony S. 2014. "The Practice of Equality." In Fustice, Democracy and the Right to Fustification, edited by Rainer Forst, 103-126. London: Bloomsbury Academic.

Lister, Andrew. 2017. "Public Reason and Reciprocity." The Fournal of Political Philosophy 25, no. 2: $155-72$.

McGuire, John. 2016. “Two Rawls Don't Make a Right: On Rainer Forst and the New Normativity." Constellations 23, no. 1: 110-21.

McNay, Lois. 2020. "The Limits of Justification: Critique, Disclosure and Reflexivity." European Fournal of Political Theory 19, no. 1: 26-46.

O’Neill, Onora. 1988a. "Abstraction, Idealization and Ideology." In Moral Philosophy and Contemporary Problems, edited by J. D. G. Evan, 55-69. Cambridge: Cambridge University Press.

-1988b. Ethical Reasoning and Ideological Pluralism. Ethics, 98, no. 4: 445-63. 
1996. Toward Fustice and Virtue. Cambridge: Cambridge University Press.

Postema, Gerald J. 1995. "Public Practical Reason: Political Practice." In Theory and Practice: Nomos XXXVII, edited by I. Shapiro and J. W. DeCew, 345-85. New York: New York University Press.

9 Rawls, John. 2001. Fustice as Fairness. A Restatement, edited by Erin Kelly. Cambridge: Harvard University Press.

Raz, Joseph. 1998. "Disagreement in Politics." The American Fournal of Jurisprudence 43, no. 1: 25-52.

Scanlon, Thomas. 1982. "Contractualism and Utilitarianism." In Utilitarianism and Beyond, edited by A. Sen and B. Williams, 103-28. Cambridge: Cambridge University Press.

Steinhoff, Uwe. 2015. "Against Equal Respect and Concern, Equal Rights, and Egalitarian Impartiality." In Do All Persons Have Equal Moral Worth?, edited by U. Steinhoff, 142-72. Oxford: Oxford University Press.

Wall, Steven. 2002. "Is Public Justification Self-Defeating?" American Philosophical Quarterly 39, no. 4: 385-94. . 2016. "The Pure Theory of Public Justification." Social Philosophy and Policy 32, no. 2: 204-26.

White, Stephen. 2015. "Does Critical Theory Need Strong Foundations?" Philosophy and Social Criticism 41, no. 3: 207-11. 